\title{
Clinical aspects of oral cancer: A case report series
}

\section{Kliniczne uwarunkowania raka jamy ustnej - opis przypadków}

\author{
Suwarna Dangore-Khasbage $\mathrm{e}^{A, B, D}$ \\ Oral Medicine and Radiology, Sharad Pawar Dental College, Datta Meghe Institute of Medical Sciences, Sawangi, India \\ A - research concept and design; $\mathrm{B}$ - collection and/or assembly of data; $\mathrm{C}$ - data analysis and interpretation; \\ $D$ - writing the article; $E$ - critical revision of the article; $F$ - final approval of article
}

Dental and Medical Problems, ISSN 1644-387X (print), ISSN 2300-9020 (online)

Dent Med Probl. 2017;54(1):85-89

Address for correspondence

Suwarna Dangore-Khasbage

E-mail: dangore_suwarna@rediffmail.com

Funding sources

none declared

Conflict of interest

none declared

Acknowledgments

We wish to thank our patients for their kind cooperation.

Received on November 1,2016

Revised on November 12, 2016

Accepted on December 2, 2016

\begin{abstract}
Oral cancer is the sixth-most common cancer globally; nevertheless, there is a wide geographical variation in its incidence all over the world. In India, it accounts for about 30\% of all new cases annually and the gingival-buccal complex (alveolar ridge, gingival-buccal sulcus, buccal mucosa) forms the most common subsite for cancer of the oral cavity, in contrast to cancer of the tongue that is more common in the Western world. There is a trend towards increasing incidence and delayed presentation of oral cancer as approximately $50 \%$ of patients present at stage III or IV. Although, oral cancer is a disease of the older age groups, many patients contract it at an early age ( $<40$ years of age), especially in high incidence countries such as India where the lower socioeconomic strata of society plays a vital role. Despite improvement in diagnostic and management techniques, the age-standardized mortality rates in oral cancer are constant, which is attributable to a failure to detect potentially malignant lesions and early stage oral cancer which precludes successful treatment.

This article describes three cases of oral squamous cell carcinoma occurring at an early age, with more emphasis on the clinical aspects of squamous cell carcinoma and measures for the prevention and early detection of oral cancer.
\end{abstract}

Key words: tobacco, squamous cell carcinoma, oral cancer

Słowa kluczowe: tytoń, rak płaskonabłonkowy, rak jamy ustnej

D0I

$10.17219 / \mathrm{dmp} / 67499$

Copyright

() 2017 by Wroclaw Medical University

and Polish Dental Society

This is an article distributed under the terms of the

Creative Commons Attribution Non-Commercial License

(http://creativecommons.org/licenses/by-nc-nd/4.0/) 
Oral cancer is the sixth-most common cancer in the world and in India oral cancer ranks in the top 3 of all cancers. ${ }^{1}$ Amongst all oral cancers, more than $90 \%$ are squamous cell carcinomas (OSCC) while the remaining 10\% of the cases are mainly melanomas, sarcomas, minor salivary gland carcinomas and metastatic cancers. ${ }^{2}$ OSCC is asymptomatic in the early stage and thus ignored by the patient, but it is known to produce high mortality and serious disturbances or discomfort in the patient as a consequence of either the tumor itself or of the treatment in the advanced stage. The incidence of OSCC is age related, which may reflect the time for the accumulation of genetic changes and duration of exposure to initiators and promoters, cellular aging, and decreased immunologic surveillance with aging. ${ }^{3}$

OSCC presents different clinical aspects which are related to the etiology, location of the tumor, evolution time, origin from precancerous lesion or condition and various risk factors. Even though the frequent clinical presentation of OSCC is a painless, rapidly increasing growth or a non-healing ulcer, it may occur in various clinical forms such as a white lesion, red lesion, mixed lesion (combination of red and white), vegetans, verrucous, and mixed forms such as ulcerous-vegetans. ${ }^{4}$ In India, ulcero-proliferative and ulcero-infiltrative presentation is quite common. This article focuses mainly on the etiology, clinical presentation and diagnostic delay of OSCC.

\section{Case presentation}

\section{Case 1}

A 38-year-old male reported with the complaint of loosening of teeth and pain in the mandibular left posterior region of the jaw for 4 months. He gave a history of oc-

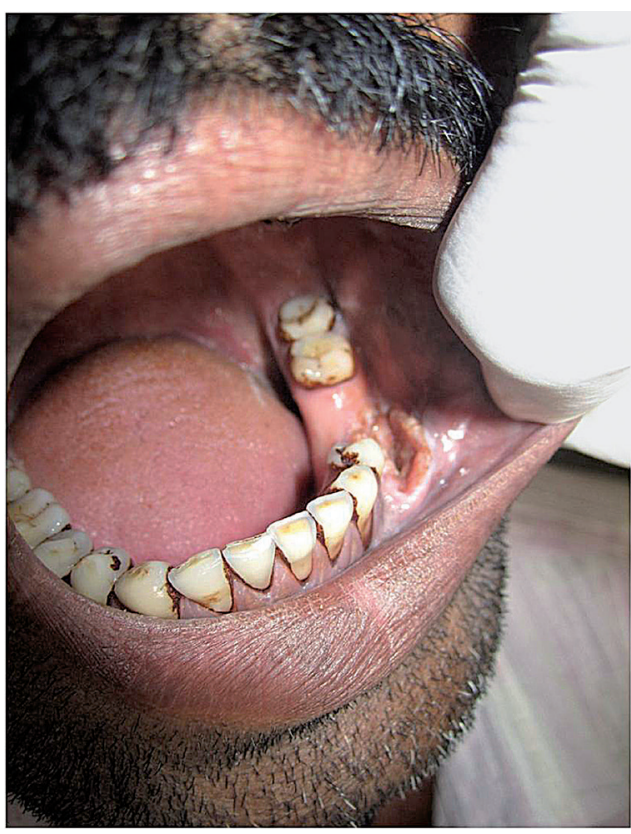

Fig. 1. Case

1 - an ulceroinfiltrative lesion on the gingiva and vestibule on the left side casional bleeding from the same site. There was no history of pus discharge, trauma, anesthesia or paresthesia in the associated area. He had a habit of paan chewing and quid keeping in the lower left buccal vestibule for 30-35 min, 8 to 10 times a day for 20 years. Oral examination revealed an ulcero-infiltrative lesion on the gingival margin in tooth 34, 35, 36 and 37 with everted edges (Fig. 1). On palpation, the lesion was tender, firm, indurated and showed mild bleeding on manipulation. Teeth in the vicinity were tender and mobile. Extraoral examination revealed the presence of a single submandibular lymph node on the same side of approximately size $1 \times 1.5 \mathrm{~cm}$, firm, non-tender and mobile. Based on the clinical features, the diagnosis was malignancy involving the gingiva and alveolus (TNM staging - T4 N1 M0). Computed tomography showed evidence of a well-defined, enhancing soft tissue density in the gingivobuccal sulcus which was eroding the outer cortex of the body of the mandible on the left side. The features were suggestive of malignancy, supporting the clinical diagnosis (Fig. 2). Histopathological confirmation of the disease was done by performing an incisional biopsy. He was treated by surgical excision of the lesion followed by plastic surgery. The skin graft, tissue flap was used to restore tissues removed from the surgical site. An H\&E stained tissue section from the surgical specimen showed the presence of neoplastic epithelial cells in the outer connective tissue capsule. The inner stroma also showed the presence of neoplastic epithelial cells arranged in the form of sheets along with a keratin pearl formation. The features were diagnostic of moderately-differentiated squamous cell carcinoma.

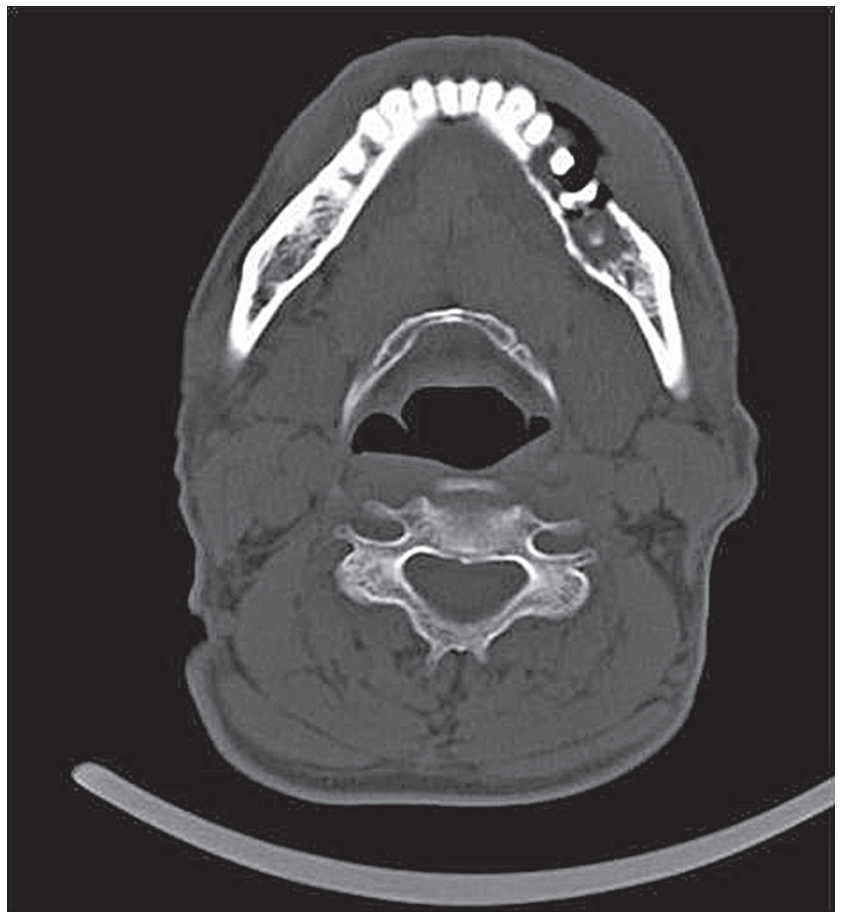

Fig. 2. Case 1 - CT scan - axial view, showing a well-defined enhancing soft tissue mass in the gingivobuccal sulcus, eroding the outer cortex of the body of the mandible on the left side 


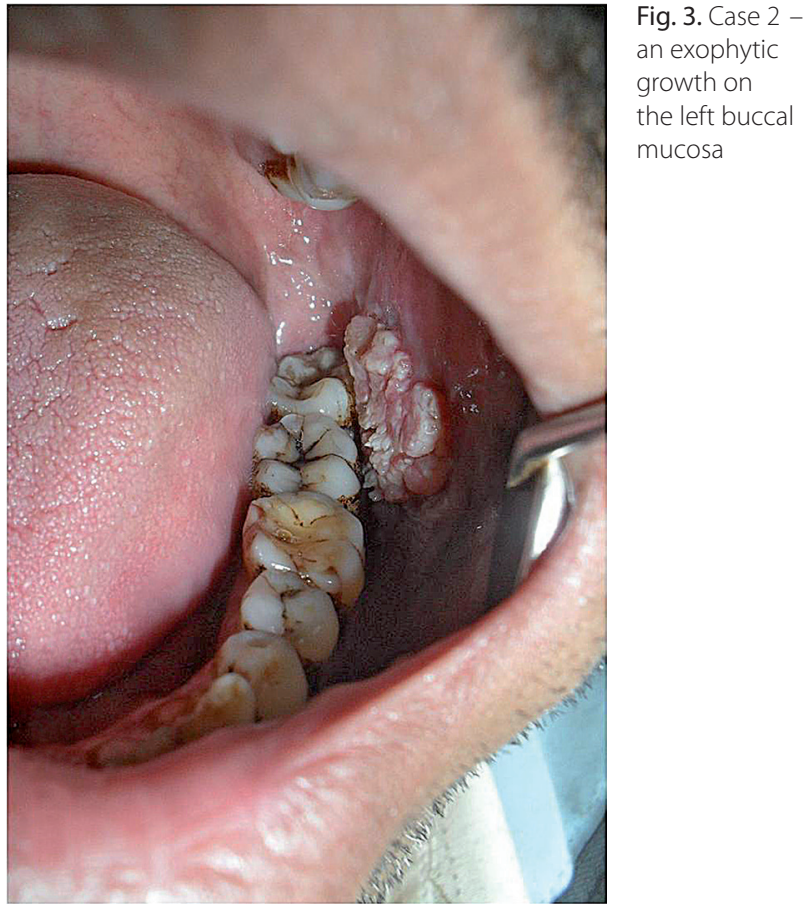

\section{Case 2}

A 36-year-old male reported with the complaint of a painless growth on the left buccal mucosa for 2 months. There was no history of discharge or paresthesia in the associated area. He had a habit of keeping tobacco lime quid in the same region 10-15 times a day for 18 years. On intraoral examination there was the presence of a single, sessile, exophytic, cauliflower-like growth on the left buccal mucosa of approximately $3 \times 2 \mathrm{~cm}$, which was white in color with distinct borders (Fig. 3). Palpation revealed that the growth was non-tender and firm. There was no regional lymphadenopathy. Considering the habit history and clinical features, the diagnosis was malignancy of the left buccal mucosa (TNM staging - T2 N0 M0). Histopathological confirmation of the disease was done by performing an incisional biopsy. He was treated by doing wide local excision of the lesion. An H\&E stained tissue section from the surgical specimen was diagnostic of moderatelydifferentiated squamous cell carcinoma. Clinical examination after 6 months following the surgery revealed uncomplicated recovery and no recurrence (Fig. 4).

\section{Case 3}

A 34-year-old male reported with the complaint of a non-healing ulcer on the right lateral border of the tongue for 3 months. The patient stated that he was healthy 3 months prior, but one day he had experienced discomfort on the right side of his tongue for which he had performed self oral inspection and noticed a small ulcer of a few millimeters in the same region. He reported

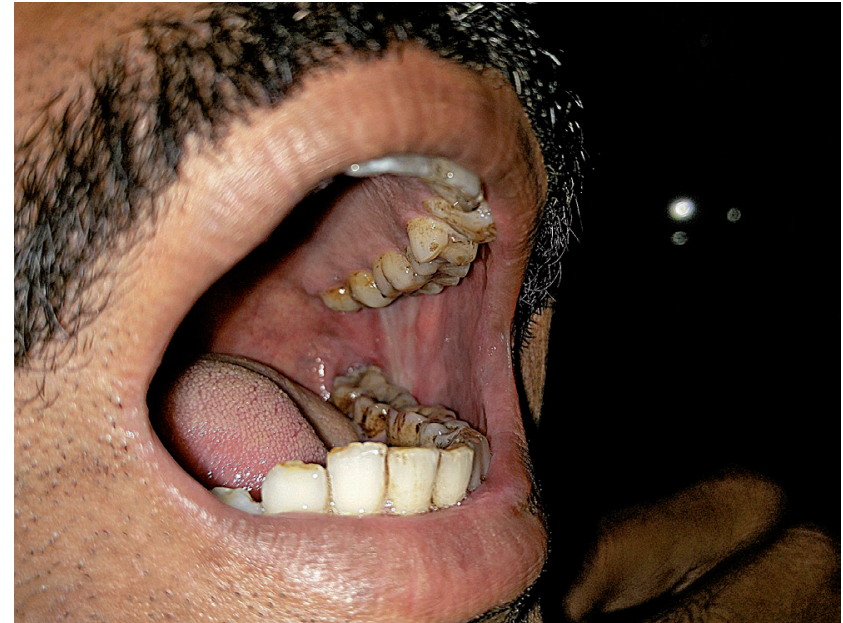

Fig. 4. Case 2 - post-operative photograph after six months following surgery

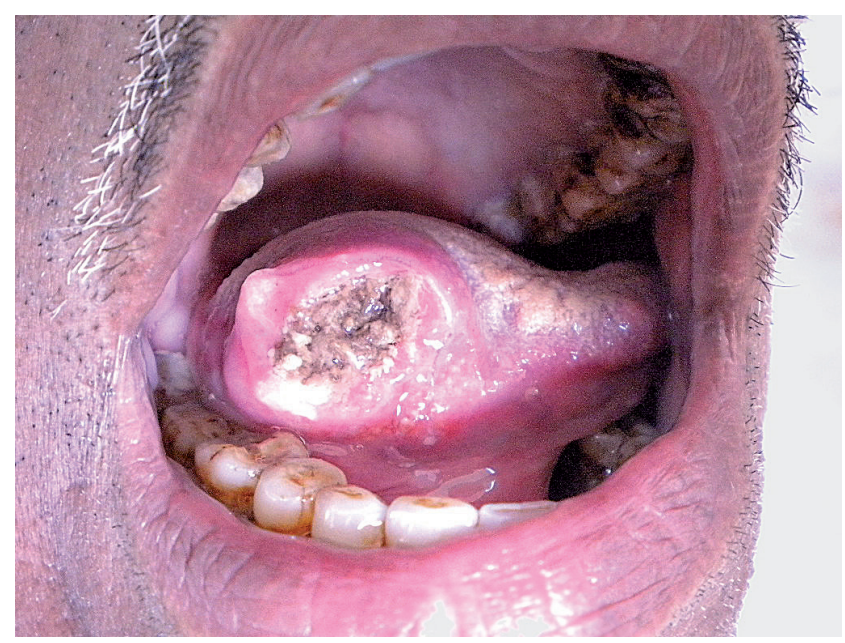

Fig. 5. Case 3 - malignant ulcer on the right lateral border of the tongue

to the physician in his home town for the problem but didn't get relief with the medications prescribed. The intraoral ulcer increased rapidly in the course of 3 months. He also gave a history of mild pain and difficulty in mastication on the right side due to the large ulcer and repeated tongue biting. There was no history of bleeding, pus discharge or paresthesia in the associated area. He had a habit of chewing paan and tobacco 4-5 times a day for 15 years. Oral examination showed the presence of a single, large $(4 \times 5 \mathrm{~cm}$ in size) ulcer with everted edges. The base of the ulcer was indurated and covered with necrotic slough (Fig. 5). Lymph node examination revealed lymphadenopathy with submental and right submandibular groups. All lymph nodes were tender, hard and partially fixed. The clinical features were diagnostic of tongue malignancy (TNM staging - T3 N2b M0). He was treated by a combination of surgery and radiotherapy after undergoing all the necessary examinations for local and distant metastases and confirmation by incisional biopsy. The 
histopathological features of the postoperative specimen were suggestive of moderately-differentiated squamous cell carcinoma.

\section{Discussion}

Oral cancer is considered a serious public health problem that causes a great deal of morbidity and mortality in the population. It is often painless or asymptomatic, so the patient usually reports for treatment at the advanced stage of the disease. Nonetheless, a diagnosis of early OSCC with a presentation of just a white lesion, red lesion, in-situ or micro-invasive carcinoma represents a real challenge for the oral diagnostician. The clinical presentation of OSCC as a white lesion with an uneven granular surface or red lesion with superficially eroded areas may be misdiagnosed as a premalignant lesion. The oral diagnostician should be aware of the initial carcinomatous changes that may take place in a premalignant lesion, as they do not respond to local treatments.

Oral cancer is a disease of increasing age, with an average age at diagnosis of about 60 years and usually the etiology is deleterious habits. ${ }^{3}$ The patients described in the present article are less than 40 years of age but according to the habit history given by them, the presence of adverse habits can be considered a probable cause for the development of cancer in them. Few previous studies have reported about the occurrence of OSCC in a younger age group $(<40)$, especially in high incidence countries such as India, Pakistan and Sri Lanka. ${ }^{5,6}$ However, a number of additional factors such as genetic susceptibility, viral infection and hormone and immune modulation are to be considered responsible for the occurrence of OSCC in young individuals, especially in females. ${ }^{7,8}$ According to Fabiana Vargas-Ferreira et al., nearly $20 \%$ of OSCC cases have unknown etiology and thus it is important to investigate other possible factors associated with the occurrence of OSCC, enabling appropriate clinical management and monitoring. ${ }^{9}$

The location of the OSCC directly correlates with the etiological factors in a particular patient. In central India, a common site for the occurrence of OSCC is the gingivobuccal vestibule. But in Western countries, the tongue is the commonest site. These site-wise differences in the incidence of oral cancer between Western countries and India may be due to a difference in the habit of tobacco usage. Tobacco smoking (cigarette) is more prevalent in Western countries while tobacco chewing, smoking (bidi) and snuffing, along with other ingredients like betel nut, Gutkha, lime, catechu, etc., are the most prevalent habits in India. The first two cases described in this paper have shown similar presentation. Due to these major etiological factors and the increasing incidence rate, it is suggested that oral cancer in India should be considered a "new epidemic".
For lip carcinoma, the etiology is usually chronic exposure to sunlight. Meanwhile, chronic trauma due to various factors, such as a fractured tooth, sharp edged teeth, root pieces or improper denture, is the most typical reason for carcinoma of the lateral border and ventral surface of the tongue. ${ }^{3,10}$ In the present article, in case 3, it is difficult to guess the probable etiology for OSCC of the lateral border of the tongue because, even though the patient has teeth with sharp cusps, he had a history of an adverse habit for 15 years.

In most cases, OSCC is asymptomatic, and pain appears only when muscles or nerves are invaded in the advanced stages of the disease. ${ }^{10}$ The common symptoms of OSCC are a painless growth, painless ulcer, loosening of teeth, exfoliation of teeth, discomfort, difficulty in swallowing, etc.

The most deadly aspect of oral cancer, like any other cancers, is its ability to spread, or metastasize. In OSCC, the spread of tumor to regional or cervical lymph nodes take place by lymphatic route usually in a sequential manner. About two-thirds of OSCC are already of substantial size and will have clinically detectable metastases to cervical lymph nodes at the time of diagnosis. ${ }^{11}$ The metastases to regional lymph nodes can be ipsilateral, contralateral or bilateral. Ipsilateral metastases are frequently associated with early stage of tumor while bilateral is often seen in advanced stage of disease, tumors of midline and posterior part of oral cavity. The higher incidence of regional metastases at the time of diagnosis is noted in OSCC involving the posterior areas of oral cavity. The tumor spread is influenced by its size. Lesions classed as T1 may show regional spread in 10 to $20 \%$ of cases, T2 lesions in 25 to $30 \%$ of cases and T3 to T4 tumors in 50 to $75 \% .^{3}$ The presence of extracapsular lymph node spread is associated with a high rate of local and regional recurrence, distant metastasis and mortality. ${ }^{11}$ Patients with metastasis need more-aggressive treatments such as combination of surgery and radiotherapy or combination of surgery and chemotherapy. It is therefore important to assess as reliably as possible whether a patient has metastases or not.

Early diagnosis is a foremost step for reducing cancer mortality, but approximately $50 \%$ of cases are diagnosed in the late stages (stages III or IV), either due to ignorance or the inaccessibility of medical care. The diagnostic delay in OSCC can be considered in three categories: ${ }^{4,12,13}$

1. Patient delay or primary delay - a delay in the time from the onset of symptoms to the initial visit to a dental or medical professional,

2. Professional delay or secondary delay - the time between the visit to a dental or medical professional and a final diagnosis, that is histological confirmation of the disease,

3. Patient and professional delay or total delay - the period of time between the final diagnosis and the beginning of treatment. 
The time period to consider as a delay in receiving treatment ranges from 21 days to 3 months according to various studies. ${ }^{12}$ In the $1^{\text {st }}$ case of the present article, there was a delay on the patient's side, but the $3^{\text {rd }}$ case can be considered a total delay, as the patient had reported to the local physician who probably could not do a correct diagnosis and thus resulted in a worsening of the disease.

The overall information affirmed in this article points to the rising prevalence of oral cancer all over the world, including India, which is attributable to diagnostic delays by both parties, the patient and the professional, and thus prevention and diagnosis of early oral cancers becomes an area of great concern.

\section{Prevention and diagnosis of oral cancer}

One of the methods for the prevention of oral cancer is to conduct a survey to evaluate the attitude of the population regarding addiction to various adverse habits and their knowledge about the causative role of habits in the development of oral cancer. With reference to this, programs should be conducted to impart awareness amongst the population related to the harmful effects of adverse habits, and also periodic de-addiction programs should be carried out especially for the rural public. Another cost-effective and feasible method to reduce overall cancer prevalence is to screen the population for early cancer and presence of precancer or potentially malignant disease.

Sankaranarayanan et al. have reported a sensitivity of $67.4 \%$ for a visual examination in detecting oral cancer in their study. ${ }^{14}$ Screenings should basically focus on the people of the high risk group such as people having a history of habit, immuno-compromised patients, elderly males, and people in a low socioeconomic group. Oral self-examination can be helpful in detecting oral cancers early. ${ }^{12,13}$

Dentists are in a unique position to promote primary preventative measures to high risk groups, and to aid in the early diagnosis and referral of suspicious oral lesions. There should be a policy to conduct regular continuing education programs for dentist, especially budding dentists, to impart knowledge about the warning signs that will aid in the diagnosis of early oral cancer.

Shwetha et al. have mentioned the objectives referring to the early diagnosis of oral cancer and various comprehensive diagnostic modalities that can be used for early detection of oral cancer like PCR, genomics and proteomics, microarrays, nanodiagnostics, etc. ${ }^{15}$ Also, they have stated the limitations in performing these methods routinely. Last but not the least is that patients must be encouraged to visit their dentist regularly, which will help to increase the rate of early detection of oral cancer.

\section{Conclusions}

The oral physician plays a vital role in the prevention of oral cancer by inducing healthy life styles and detecting the potentially malignant conditions. They can reduce oral cancer related morbidity and mortality by diagnosing an early stage oral cancer. But, to achieve this goal, they should have in-depth knowledge about the clinical aspects of oral cancer. The Indian oral cancer scenario is relatively different from other parts of the world in terms of its etiology, clinical presentation, sociology, economy and diagnostic delay.

\section{References}

1. Prasad LK. Burden of oral cancer: An Indian scenario. J Orofac Sci. 2014;6:77.

2. Waal VI, Bree DR, Brakenhoff R, Coebergh JW. Early diagnosis in primary oral cancer: Is it possible? Med Oral Patol Oral Cir Bucal. 2011;16:e300-305.

3. Epstein JB. Oral cancer. In: Burket's Oral Medicine. Diagnosis and treatment. 10 th ed. Delhi, India: Harcourt Pvt Ltd;2003:194-234.

4. Bolesina N, Femopase FL, Silvia A, Blanc L, Morelatto RA, Olmos MA. Oral squamous cell carcinoma clinical aspects, oral cancer. InTech. 2012. Available from: http://www.intechopen.com/books/oralcancer/oral-squamouscell- carcinoma-clinical-aspects

5. Warnakulasuriya S. Global epidemiology of oral and oropharyngeal cancer. Oral Oncol. 2009;45:309-316.

6. Effiom OA, Adeyemo WL, Omitola OG, Ajayi OF, Emmanuel MM, Gbotolorun OM. Oral squamous cell carcinoma: A clinicopathologic review of 233 cases in Lagos, Nigeria. J Oral Maxillofac Surg. 2008; 66:1595-1599.

7. Falaki F, Dalirsani Z, Pakfetrat A. Clinical and histopathological analysis of oral squamous cell carcinoma of young patients in Mashhad, Iran: A retrospective study and review of literatures. Med Oral Patol Oral Cir Bucal. 2011;16:e473-477.

8. Soudry E, Preis M, Hod R. Squamous cell carcinoma of the oral tongue in patients younger than 30 years: Clinicopathologic features and outcome. Clin Otolaryngol. 2010;35:307-312.

9. Fabiana VF, Nedel F, Etges A, Gomes APN, Furuse C, Tarquinio SBC. Etiologic factors associated with oral squamous cell carcinoma in non-smokers and non-alcoholic drinkers: A brief approach. Braz Dent J. 2012;23:586-590.

10. Chi AC. Epithelial pathology. In: Neville BW, Damm DD, Allen CM, Bouquot JE, ed. Oral \& Maxillofacial Pathology. $2^{\text {nd }}$ ed. Noida, India: Elsevier; 2002:409-421.

11. Massano J, Regateiro FS, Januario G, Ferreira A. Oral squamous cell carcinoma: Review of prognostic and predictive factors. Oral Surg Oral Med Oral Pathol Oral Radiol Endod. 2006;102:67-76.

12. Joshi P, Nair S, Chaturvedi P, Nair D, Agarwal JP, D'Cruz AK. Delay in seeking specialized care for oral cancers: Experience from a tertiary cancer center. Indian J Cancer. 2014;51:95-97.

13. Kerdpon D, Sriplung $H$. Factors related to delay in diagnosis of oral squamous cell carcinoma in southern Thailand. Oral Oncol. 2001;37:127-131.

14. Sankaranarayanan R, Ramadas K, Thara S, Muwonge R, Thomas G, Anju G. Long term effect of visual screening on oral cancer incidence and mortality in a randomized trial in Kerala, India. Oral Oncol. 2013;49:314-321.

15. Shwetha KN, Vanishri HC, Dominic A, Sowmya SV, Roopa RS. Recent advances in diagnosis of oral cancer. JDOR 2016;12:19-21. 